\title{
A Comparative Finite Element Analysis Study for Micromotion around Basally Osseointegrated and Crestal Osseointegrated Implant in Mandibular First Molar Region
}

\author{
${ }^{1}$ Gunjan Gupta, ${ }^{2}$ Varun Goyal
}

\begin{abstract}
Aims: Crestal and basal implants are endosseous aids to create osseointegrated points of retention. These two types of implants are not only differentiated by the way they are inserted, but also by the way the forces are transmitted. The purpose of this study is to compare the micromotion between two crestal and one basal implant-supported crown, when the mesiodistal space is $14 \mathrm{~mm}$ in mandibular first molar region.
\end{abstract}

Materials and methods: A three-dimensional finite element method was used to evaluate the micromotion in two osseointegrated crestal implants and one basally osseointegrated implant when the mesiodistal space is $14 \mathrm{~mm}$ in mandibular first molar region. The loads were applied according to cusp-marginal ridge relation. A total of $333 \mathrm{~N}$ and $645 \mathrm{~N}$ of load was applied to premolar and each molar respectively. The results were analyzed using von Mises criteria.

Results: The results of the comparison of crestal and basal implants to replace mandibular first molar demonstrated that micromotion in crestal implant (14.545) was less than in basal implant (36.031).

Conclusion: Thus, within the limitations of this study, it can be concluded that the use of two crestal implants to replace a missing mandibular first molar with mesiodistal edentulous space of $14 \mathrm{~mm}$ is a preferable option as compared with basal implant to replace a missing mandibular molar.

Keywords: Basal implant, Crestal implant, Micromotion.

How to cite this article: Gupta G, Goyal V. A Comparative Finite Element Analysis Study for Micromotion around Basally Osseointegrated and Crestal Osseointegrated Implant in Mandibular First Molar Region. Int J Oral Implantol Clin Res 2016;7(2):30-33.

Source of support: Nil

Conflict of interest: None

\footnotetext{
${ }^{1}$ Senior Resident, ${ }^{2}$ Reader

${ }^{1}$ Department of Prosthodontics, Post Graduate Institute of Medical Sciences, Rohtak, Haryana, India

${ }^{2}$ Department of Orthodontics, Sudha Rustagi College of Dental Sciences \& Research, Faridabad, Haryana, India

Corresponding Author: Gunjan Gupta, Senior Resident Department of Prosthodontics, Post Graduate Institute of Medical Sciences, Rohtak, Haryana, India, Phone: +91-8585902828, e-mail: aagunjangupta@gmail.com
}

\section{INTRODUCTION}

The ideal goal of modern dentistry is to restore the patient to normal contour, function, comfort, esthetics, speech, and health. ${ }^{1}$ Though the science of restoration of missing teeth is as old as 300 BC, with the Egyptians employing a variety of methods to secure the prosthetic teeth, the successful replacement of lost natural teeth by dental implants is a major advance in dentistry. ${ }^{2}$ What makes the implant dentistry unique is the ability to achieve this goal regardless of the atrophy, disease, or injury of the stomatognathic system.

The type of implant chosen to replace the missing tooth is an important objective in biomechanical optimization of dental implants. According to the well-known implantological rules for dental restorations, the crestal implants are indicated in situations when an adequate vertical bone supply is given. ${ }^{3}$ It is also stated that the basal implantology is a new category with new, broad indications and almost no limitations. Basal implants transmit loads primarily (and initially only) into the cortical bone areas. ${ }^{4}$

Various studies have been done to compare the single implant, wide diameter implant (WDI), and two implants that supported a single crown for replacing the mandibular first molar. ${ }^{5-8}$ It was found that the placing of the two implants to replace a mandibular molar was the preferable option. At the same time, it was found that the two implants supporting a single crown will create a furcation and hence, an oral hygiene problem. Therefore, the two implants supporting two separate premolars were considered in the present study.

So, the aim of this study was to measure and compare micromotion in the two osseointegrated crestal implants supporting two premolar crowns and basally osseointegrated implant-supported single molar using finite element analysis in the mandibular first molar region.

\section{MATERIALS AND METHODS}

A finite element program, ANSYS version 12.1, was used for the study. The implant was assumed to be placed in the region of first molar of the mandible. The models were provided in close approximation to the in vivo geometry. 


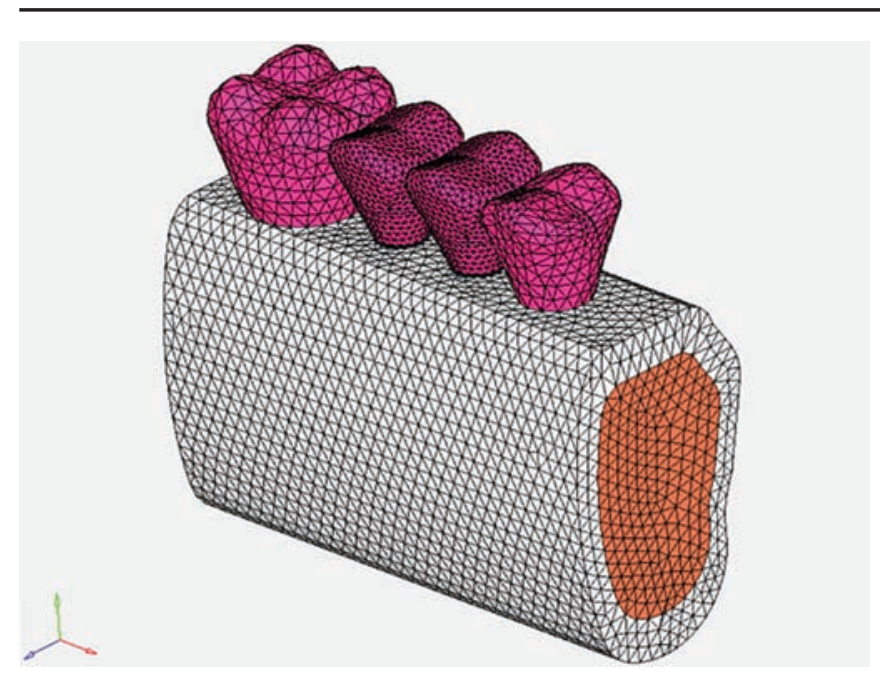

Fig. 1: Meshed model of implant and bone assembly for crestal implant

First, the section of the mandibular bone in first molar region was constructed with a height of $22.00 \mathrm{~mm},{ }^{9}$ buccolingual width of $11 \mathrm{~mm}$, and mesiodistal width of edentulous space of $14 \mathrm{~mm} .{ }^{10}$ The thickness of the labial cortical plate was taken as $2.00 \mathrm{~mm}$ and lingual cortical plate as $2.5 \mathrm{~mm} .{ }^{11}$ The density of bone was taken as D2, as it is the most common bone density observed in the mandible. ${ }^{1}$

A three-dimensional finite element model of root form square thread type implant system was generated. The dimensions of the crestal implant were $4.0 \mathrm{~mm}$ diameter and $15.00 \mathrm{~mm}$ length. The dimensions of basal implant were $10.00 \mathrm{~mm}$ in length and $10.00 \mathrm{~mm}$ of disk diameter.

The implant was inserted according to the section of the bone. Suitable abutment was screwed onto the implant. The anatomy of crown structure of the crestal implant was modeled as mandibular premolar (Fig. 1) and that of basal implant was modeled as mandibular first molar according to Wheelers and Nelson ${ }^{12}$ (Fig. 2).

For the execution and accurate analysis of the program and interpretation of the results, two material properties were utilized, i.e., Young's modulus and Poisson's ratio

Table 1: Mechanical properties of different materials used in the model ${ }^{13}$

\begin{tabular}{lll}
\hline Materials & $\begin{array}{l}\text { Young's modulus } \\
(E)(\mathrm{MPa})\end{array}$ & $\begin{array}{l}\text { Poisson's } \\
\text { ratio }(\mu)\end{array}$ \\
\hline Cortical bone & 13,400 & 0.30 \\
Cancellous bone & 1,370 & 0.30 \\
Implant (titanium alloy) & 110,000 & 0.33 \\
Nickel chromium & 203,600 & 0.30 \\
Porcelain & 6,900 & 0.28 \\
Zinc phosphate cement & 22,000 & 0.35 \\
Enamel & 41,400 & 0.3 \\
Dentin & 18,600 & 0.31 \\
Pulp & 2 & 0.45 \\
Periodontal ligament & 69 & 0.45 \\
\hline
\end{tabular}

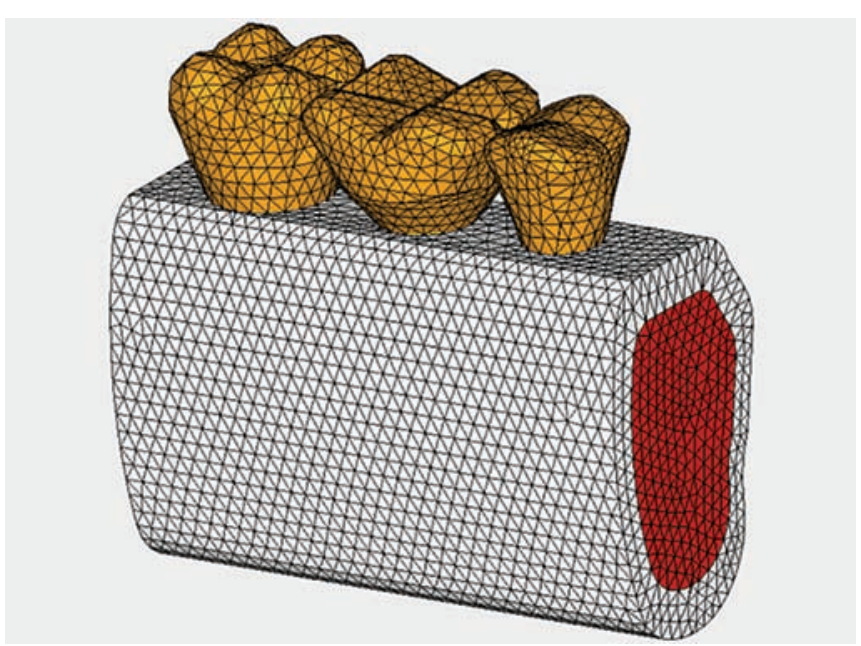

Fig. 2: Meshed model of implant and bone assembly for basal implant

as given in Table 1. The cortical bone, cancellous bone, and implant with abutment were presumed to be linearly elastic, homogenous, and isotropic.

Constraints were applied on the ends of the model in all the three axes and omitting support at the bottom permitted bending of the model.

The magnitude of applied loads was within physiologic limits and direction of application of the loads simulated the clinical conditions. Cusp-marginal ridge is the most natural type of occlusion and is found in $95 \%$ of all adults. ${ }^{14}$ Therefore, the loads were applied according to cuspmarginal ridge relation. A total of $333 \mathrm{~N}$ and $645 \mathrm{~N}$ of load was applied to premolar and each molar respectively. ${ }^{15}$ The loads on premolar were applied on the buccal cusp and distal fossa, whereas on first molar, it was applied on central fossa, distal marginal ridge, mesiobuccal and distobuccal cusps, and for the second molar, it was applied on mesial marginal ridge, central fossa, distal marginal ridge, mesiobuccal, and distobuccal cusps. The loads were applied perpendicular to the points of centric contacts.

These models were analyzed by the processor, i.e., solver, and the results were displayed by postprocessor of the finite element software (ANSYS, version 12.1) in the form of color-coded maps using von Mises stress analysis.

\section{RESULTS}

- Model I: The displacement on implant was found to be $14.545 \mu \mathrm{m}$, which was less than that found on the basal implant model (Table 2 and Fig. 3).

Table 2: Micromotion of implant

\begin{tabular}{llll}
\hline & & $\begin{array}{l}\text { Crestal implant } \\
\text { (Model I) }\end{array}$ & $\begin{array}{l}\text { Basal implant } \\
\text { (Model II) }\end{array}$ \\
\hline Displacement $(\mu \mathrm{m})$ & Minimum & 4.672 & 7.124 \\
& Maximum & 14.545 & 36.031 \\
\hline
\end{tabular}




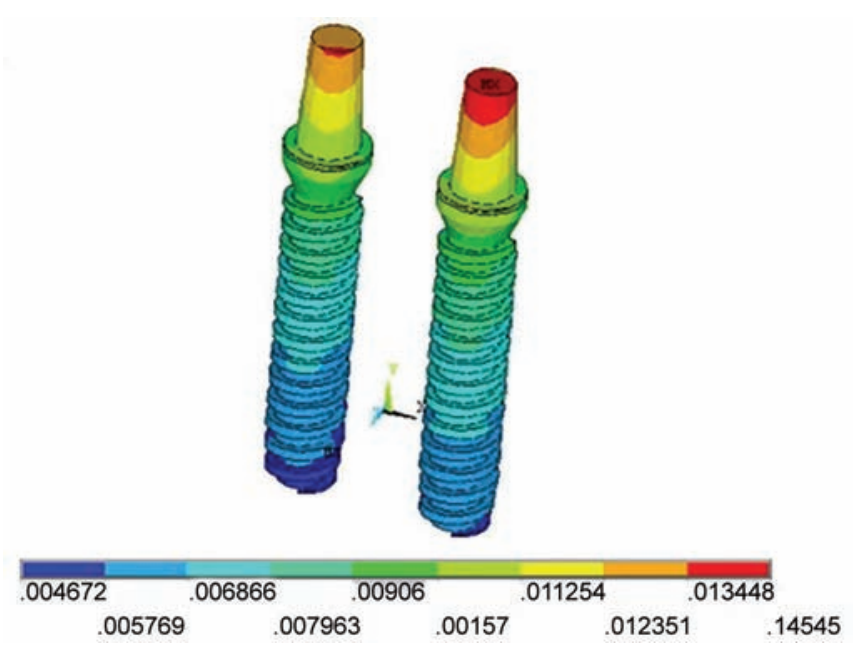

Fig. 3: Micromotion for crestal implant

- Model II: The displacement on implant was found to be $36.031 \mu \mathrm{m}$, which was more than that found on the crestal implant model (Fig. 4).

\section{DISCUSSION}

Permanent first molar is one of the most significant tooth in the oral cavity. Caries is the most common cause of permanent first molar extraction in all age groups followed by periodontal problems. Mandibular molars are more adversely affected by caries as compared with maxillary molars. ${ }^{16}$

The molar mesiodistal dimension usually ranges from 8 to $14 \mathrm{~mm}$. When the mesiodistal dimension is 8 to $12 \mathrm{~mm}$, a 5 to $6 \mathrm{~mm}$ diameter implant is suggested to reduce stress to the implant system. However, when it is 12 to $14 \mathrm{~mm}$, the treatment plan of choice is less obvious. If one $4 \mathrm{~mm}$ diameter implant is placed to support a crown with a mesiodistal dimension of $14 \mathrm{~mm}$, this may create a 4 to $5 \mathrm{~mm}$ cantilever on the marginal ridges. The magnified occlusal forces (especially important in parafunction) may cause bone loss, complicate home care, increase abutment screw loosening, and increase abutment and implant failure because of overload. ${ }^{10}$

In the last decade, the use of WDIs (diameter $>3.75 \mathrm{~mm}$ ) has increased, especially in the posterior jaw, because it is generally accepted that WDIs improve the ability of posterior implants to tolerate the occlusal forces, create a wider base for proper prosthesis, and avoid the placement of two standard-size implants $(3.75 \mathrm{~mm})$ at one site to obtain a double-root prosthetic tooth. ${ }^{8}$

The most common complication of one regular $4 \mathrm{~mm}$ diameter implant to replace a molar is abutment screw loosening. When the mesiodistal dimension permits, two 3.5- to 4-mm diameter implants should be considered to restore the region to improve stress reduction, and, in turn, reduce the incidence of abutment screw loosening. ${ }^{1}$
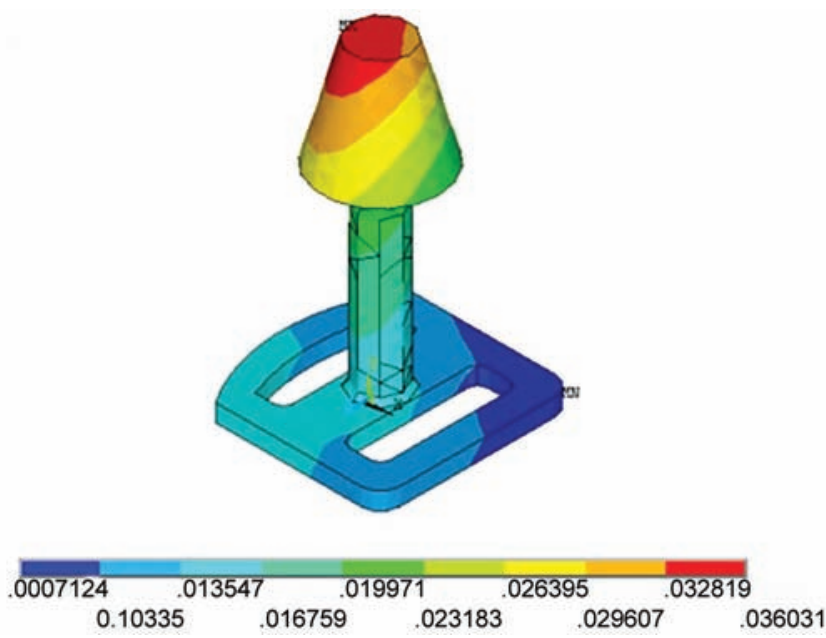

Fig. 4: Micromotion for basal implant

In a 3-year report of posterior first molar replacements, Balshi et al ${ }^{6}$ found implant screw loosening was a common complication when one implant replaced the missing tooth $(48 \%)$ and was reduced to $8 \%$ when two splinted implants replaced the missing mandibular first molar.

In the present study, two crestal implants of $4 \mathrm{~mm}$ diameter were chosen to replace a missing mandibular first molar when the mesiodistal dimension of the edentulous space was $14 \mathrm{~mm}$. The distance between the two implants was kept as $3 \mathrm{~mm}$, and the distance between the implant and adjacent tooth was kept as $1.5 \mathrm{~mm} .{ }^{10}$ As reviewed in literature that two standard size implants supporting a single prosthesis produce a furcation ${ }^{1}$ and, hence, create problems; therefore, two premolar size crowns were modeled in the present study. Also, in the present study, basal implant of $10 \mathrm{~mm}$ disk diameter was selected to replace mandibular first molar with mesiodistal space of $14 \mathrm{~mm}$. The disk, because of its large diameter, i.e., greater than the widest implant available in the crestal assembly, was chosen. The disk provides the stability to the implant and resists displacement when the masticatory forces are applied.

For complicated geometries, such as mandible, it is very difficult to achieve an analytical solution. Therefore, the use of numerical methods, such as finite element method is required. For ethical reasons, in vivo measurements cannot be done inside the bone, so, finite element analysis was used to measure the stress along implant bone interface. ${ }^{17}$ Masticatory loads induce axial forces and bending moments that result in stress gradients in the implant as well as in the bone. finite element method allows us to safely predict stress distribution in the contact area of the implants with cortical bone and in the trabecular bone.

\section{CLINICAL IMPLICATIONS}

Within the limitations of this study, it is clear that the two crestal implants supporting the mandibular first 
molar showed less micromotion than the basal implant replacing a mandibular molar when the mesiodistal length of the edentulous space is $14 \mathrm{~mm}$. But the micromotion values for the basal implants were found within the physiologic limits; therefore, basal implants can also be considered as an alternative treatment option. When the mesiodistal space is 12 to $14 \mathrm{~mm}$, then the primary goal is to obtain at least $14 \mathrm{~mm}$ space. This additional space is gained by either enameloplasty, orthodontics, or the diagonal placement of implants as the available space does not permit the placement of two crestal implants. Then, in such clinical situations, basal implants can be used.

\section{CONCLUSION}

Despite the limitations of the methodology that considered the bone homogeneous, the results of static load and linear analysis support the following conclusions:

- The micromotion observed was less for crestal implant as compared with basal implant.

- Basal implant showed micromotion, which was within the physiologic limits.

- Basal implants can be considered as an alternative treatment option in case when the mesiodistal width is 12 to $14 \mathrm{~mm}$.

Thus, within the limitations of this study, it can be concluded that the use of two crestal implants to replace a missing mandibular first molar with mesiodistal edentulous space of $14 \mathrm{~mm}$ is a preferable option as compared with basal implant to replace a missing mandibular molar.

\section{REFERENCES}

1. Misch, CE. Contemporary implant dentistry. 3rd ed. St. Louis: Elsevier Mosby; 2012. p. 3, 136, 670-671.

2. Steiggenga JT, Al-Shammary KF, Nociti FH, Misch CE, Wang H-L. Dental implant design and its relationship to long term implant success. Implant Dent 2003 Dec;12(4):306-317.
3. Thde S. Comparison of basal and crestal implants and their modus of application. Smile Dental J 2009;4(1):36-46.

4. Ihde S. Dental implant treatment using cortical bone or corticalized bone areas. CMF Implant Dir 2010 Sep;5(4):99-123.

5. Bahat $\mathrm{O}$, Handelsman M. Use of wide implants and double implants in the posterior jaw: a clinical report. Int J Oral Maxillofac Implants 1996 May-Jun;11(3):379-386.

6. Balshi TJ, Hernandez RE, Pryszlak MC, Rangert B. A comparative study of one implant versus two replacing a single molar. Int J Oral Maxillofac Implants 1996 May-Jun;11(3):372-376.

7. Balshi TJ, Wolfinger GJ. Two-implant-supported single molar replacement: interdental space requirements and comparison to alternative options. Int J Periodont Restor Dent 1997 Oct;17(5):427-435.

8. Degidi M, Piattelli A, Iezzi G, Carinci F. Wide-diameter implants: analysis of clinical outcome of 304 fixtures. J Periodontol 2007 Jan;78(1):52-58.

9. Xie Q, Wolf J, Ainamo A. Quantitative assessment of vertical heights of maxillary and mandibular bones in panoramic radiographs of elderly dentate and edentulous subjects. Acta Odontol Scand 1997 Jun;55(3):155-161.

10. Misch, CE. Dental implant prosthetics. 1st ed. St. Louis: Elsevier Mosby; 2005. p. 357, 359-361.

11. Katranji A, Misch K, Wang HL. Cortical bone thickness in dentate and edentulous human cadavers. J Periodontol 2007 Jun;78(5):874-878.

12. Wheelers A, Nelson SJ. Dental anatomy, physiology, and occlusion. 8th ed. St. Louis: Elsevier Saunders; 2005. p. 251-261, 297-322.

13. de Paula GA, da Mota AS, Moreira AN, de Magalhaes CS, Cornacchia TPM, Cimini CA. The effects of prosthesis length and implant diameter on the stress distribution I tooth implant supported prosthesis - a finite element analysis. Int J Oral Maxillofac Implants 2012 May-Jun;27(3):e19-e28.

14. Schillingburg, HT.; Hobo, S.; Whitsett, LD.; Jacobi, R.; Brackett, SE. Fundamentals of fixed prosthodontics. 3rd ed. Chicago, IL: Quintissence Publishing Co; 1997. p. 341-342.

15. Anusavice, KJ. Phillip's science of dental materials. 11th ed. St. Louis: Elsevier Saunders; 2003. p. 93.

16. Januja OS, Hassan SH, Azad AA, Ibrahim MW, Luqman U, Qureshi SM. Reasons and pattern of first molar extraction: a study. Pakistan Oral Dent J 2011 Jun;31(1):51-54.

17. Benzing UR, Gall H, Weber $\mathrm{H}$, Biomechanical aspects of two different implant-prosthetic concepts for edentulous maxillae. Int J Oral Maxillofac Implants 1995 Mar-Apr;10(2):188-198. 